\title{
Turnout and the (effective) number of parties at the national and district levels: $A$ puzzle-solving approach
}

\section{Bernard Grofman}

University of California, Irvine, USA

\section{Peter Selb}

University of Konstanz, Germany

\begin{abstract}
Blais (2006) and Blais and Aarts (2006) in their review essays on voter turnout call attention to a striking puzzle about the link between electoral systems and turnout, namely that, ceteris paribus, proportional representation (PR) systems with many parties appear to have higher national-level turnout than single-member district (SMD) plurality systems with few parties, yet turnout does not increase with the (effective) number of parties (ENP) at the national level. To address this puzzle we turn to district-specific within-nation panel data from Switzerland and Spain. Our countryspecific findings allow us to explain the national-level puzzle as essentially an ecological artefact, in that the multi-member districts found in proportional systems, on average, do exhibit higher turnout than SMDs, but turnout does not rise with district magnitude, $m$, once we move beyond the contrast between $m=1$ and $m>1$. Using a more sophisticated approach to measuring political competition that does not treat all PR systems as generating identical turnout incentives (Grofman and Selb, 2009), we seek to explain this puzzle by showing both empirically and theoretically that (I) proportionality does not necessarily increase with district magnitude, and (2) competition does not necessarily increase with district magnitude.
\end{abstract}

Corresponding author:

Bernard Grofman, Center for the Study of Democracy, University of California, Irvine 315I Social Science Plaza, Irvine CA 92697-5100, USA.

Email: bgrofman@uci.edu 


\section{Keywords}

disproportionality, district magnitude, effective number of parties, electoral systems, party competition, voter turnout

\section{Introduction}

Empirical evidence is overwhelming that nationwide turnout is higher on average in proportional representation (PR) systems than in countries with pluralitarian/majoritarian elections. This finding survives even when we control for other factors, such as the nature of registration procedures, weekend voting, compulsory voting, and so on, that also impact turnout (for an extended survey of the theoretical and empirical literature on this topic, see Blais, 2006; Blais and Aarts, 2006; see also Franklin, 2004). ${ }^{1}$

Two main explanations for the greater average turnout under PR have been emphasized in the previous literature. Both suggest a strong linkage between turnout and the number of political parties.

The first links higher turnout directly to the number of parties. PR elections are thought to facilitate the emergence of multiple, ideologically distinct parties which give voters a wider range of choices (see, e.g., Cox, 1997, 1999). This broadened range of options should make it more likely that voters will find some party to support whose policies they are enthusiastic enough about (ideologically close enough to) to warrant their paying the costs of political participation. ${ }^{2}$ Also, ideological propinquity can lead to the development of partisan identification that is linked to more attentiveness to politics and a higher likelihood of political involvement (see, e.g., Crepaz, 1990).

A second explanation is indirectly linked to number of parties by way of district magnitude. When proportionality is high, there should be fewer wasted votes, so high proportionality should be linked to instrumental incentives for higher turnout. And, since the threshold of exclusion declines with $m$, the higher the district magnitude (and thus, concomitantly, the higher the expected number of parties), the more proportional we might expect outcomes to be. In the phrasing of Blais and Aarts (2006: 4): in the PR systems, as district magnitude increases, 'even small parties can win seats, and so few people have the impression that their vote does not count'. ${ }^{3}$ A related argument is that in first-past-the-post systems, there are often many safe seats in single-member constituencies (SMDs), seats where there is little uncertainty about the eventual winner, and that this lack of competition depresses turnout. But such plurality-based SMD elections should also be associated with low competition, and thus situations with few parties should be associated with low turnout.

If either or both of these explanations were correct, then it would seem that one ought to see turnout at its highest, ceteris paribus, in systems with the most parties, where ENP (the Laakso-Taagpera index of effective number of parties: Laakso and Taagepera, 1979) is used to measure the number of parties, since such systems might also be expected to be the most competitive and the most proportional. Yet, at least with cross-national data, as Blais and Aarts (2006: 11) summarize the research they report on in Table 5 of their paper: 'most studies report a negative relationship [between 
number of parties and turnout]' ${ }^{4}$ The aim of this article is to address this 'puzzle' of turnout being higher in PR systems yet not rising with the (effective) number of parties. We take the view (Grofman, 2001b, 2001c) that puzzles such as this can be an inspiration for theory building.

In order to better address the puzzle of turnout not rising with the number of parties, we draw both on new measurement (the Grofman and Selb [2009] measure of political competition) and new data. In particular, we follow up on a suggestion in Blais and Aarts (2006: 185) to look at data at the district level within individual countries.

The two countries we have chosen - Spain and Switzerland - each display a considerable variation in district magnitude $;^{5}$ they also show a range of variation in the effective number of parties at the district level. ${ }^{6}$ As Blais and Aarts (2006) observe, while the evidence of lower mean turnout in SMD plurality systems than in PR systems is compelling, the nature of this evidence is (a) cross-sectional rather than longitudinal, and (b) based on data aggregated at the national level. The reliance on cross-sectional data aggregated at the national level leaves open the possibility that the multivariate models used to test the hypothesis inadvertently omitted variables linked to cross-national differences that could 'explain away' the effects attributed to electoral systems, or neglected interaction effects.

Also, some important countervailing arguments suggesting that the relationship between the number of parties and turnout should actually be negative are applicable only at the national level. In particular, it seems plausible that the presence of multiple parties makes more likely the existence of coalition governments, and it is claimed that voters' inability to assign responsibility and accountability for the acts of coalition governments will diminish voter incentives to turn out to vote (Jackman, 1987; see also Jackman and Miller, 1995). ${ }^{7}$ Relatedly, Powell (2000) has argued that elections in larger party systems are less decisive in that they often result in coalition governments where negotiation among elites, rather than the election outcome itself, determines the executive responsibility. But neither of these explanations is relevant to explaining withincountry differences in turnout as a function of the number of parties found in particular constituencies. ${ }^{8}$ Thus, looking at within-country evidence on turnout linkages should help us make better sense about what mechanisms are actually driving the observed relationships between turnout and variables such as the effective number of parties.

At the national level, Switzerland has about twice as many effective electoral parties as Spain (namely six), yet it has a lower turnout. However, we must be alert to the potential for ecological confounds such as Simpson's paradox (Simpson, 1951; Wainer and Brown, 2004), in which relationships observed in the aggregate need not be characteristic of subunits, and vice versa. But, while in principle we could observe a negative relationship between turnout and ENP at the cross-national level and a positive relationship at the consitutency level within any given country (cf. Grofman, 1989), by focusing on district-level comparisons we are able to show that, apart from the special case of SMDs, what is true cross-nationally is roughly speaking also true within-nation. The link between the effective number of parties and turnout is not positive. The patterns we find, however, are complex, with mean turnout either lower in SMDs than in multi-seat constituencies (Switzerland) or more or less identical between the two groupings (Spain); yet in both countries, for district magnitude, $m$, greater than 1 , we also find turnout falling with increasing numbers of parties. 
If we combine data where there is a no relationship with data where there is a negative relationship, absent ecological confounds, we expect, on average, a negative link between the effective number of parties and turnout. Also, in the aggregated data, we expect the negative relationship for the MMDs to swamp the positive link within SMDs, since PR in MMDs is the more common form of election mechanism. Moreover, something else we find for our country-specific analyses, namely that the average turnout in the MMDs within each country is higher than the average turnout for the SMDs in that same country, helps us understand the puzzle of why turnout can be higher for PR systems using MMDs than for plurality/majority systems using SMDs without turnout rising with the number of parties.

Of course, this explanation of the cross-national differences in turnout between PR and non-PR countries taking place without a positive link (at least for the MMDs) between turnout and the effective number of parties triggers a new puzzle, namely why, at the district level, holding country constant, we find a negative (or at least a non-positive) link between the number of parties and turnout for districts using PR. It might appear that we have made one puzzle go away only to be left with a new puzzle of comparable or greater magnitude.

In the remainder of the article, we seek to explain this new puzzle by looking at how turnout is linked to a variety of other variables, for example, competitiveness, proportionality and district magnitude, at the within-country constituency level.

Our explanation of the puzzle of a negative relationship between turnout and the effective number of parties at the district level rests on two arguments. First, using a more sophisticated approach to measuring political competition that does not treat all PR systems as generating identical turnout incentives (Grofman and Selb, 2009), we can show both empirically and theoretically that competition does not necessarily increase with the number of parties. Second, we show both empirically and theoretically that proportionality does not necessarily increase with district magnitude.

Thus, the two reasons commonly given for why incentives for turnout in PR systems should rise with the number of parties - a greater proportionality that reduces wasted votes, and a greater competitiveness as we increase $m$, and increase concomitantly the number of parties - are either erroneous or overstated. We also look at differences in the nature of electoral competition in Switzerland and Spain that may help explain the fact that the relationships between turnout and other factors such as competition are not the same in the two countries.

\section{Link between turnout and ENP at the district level: Evidence from Switzerland and Spain}

For cross-national data we know that the effective number of parties nationwide tends to be negatively related to variations in mean turnout. But what about the link between turnout and the (effective) number of parties within a single country where we can observe the two variables in districts (including both SMDs and MMDs of varying magnitudes) with some considerable variation in both district magnitude and the effective number of parties?

As we see from Figure 1 for Switzerland (left panel) and Spain (right panel), the link between the effective number of parties and turnout is not what common sense (and 


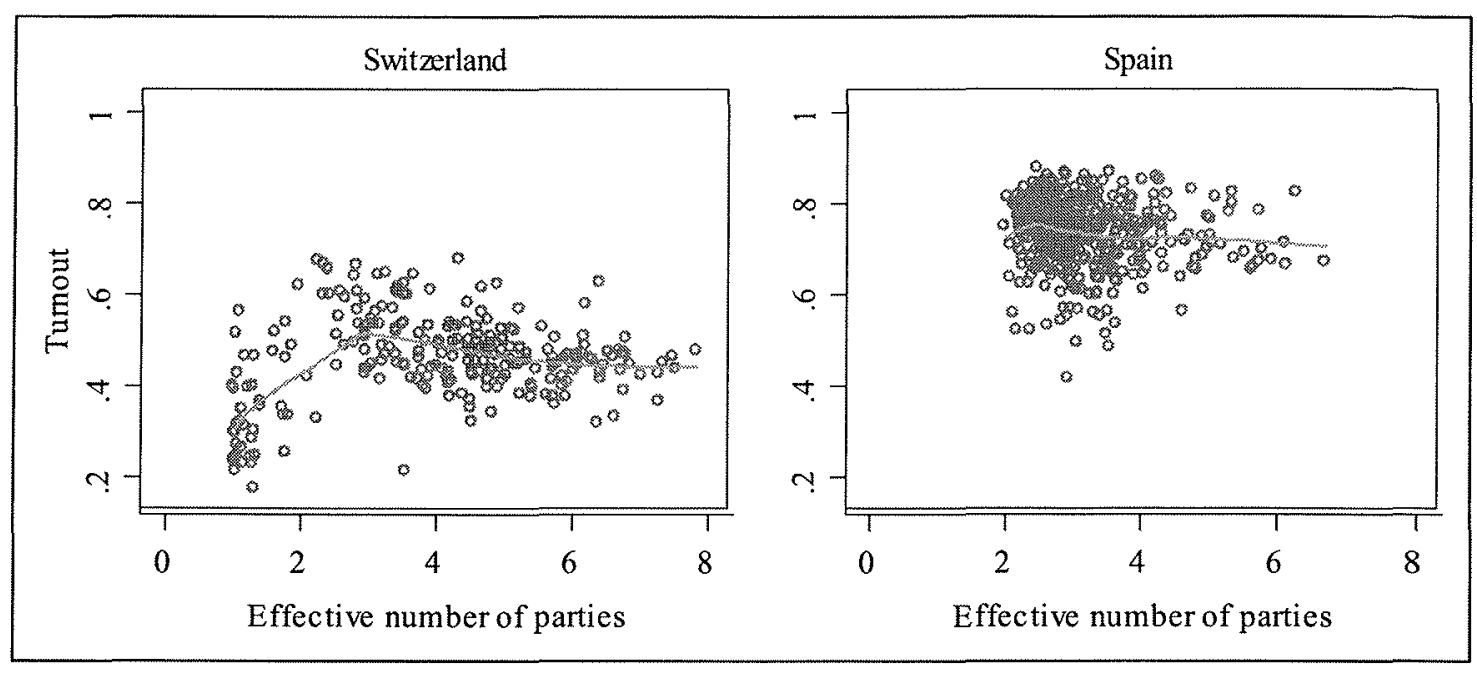

Figure I. Turnout versus the effective number of parties (votes) in Swiss National Council elections, 197I-2007 $(n=243)$ and in Spanish elections to the Lower Chamber, 1977-2004 $(n=$ 468) for all districts. Lines represent locally weighted regression fit (LOWESS). Note: Compulsory voting district observations have been excluded

electoral theory) would lead us to expect. While the correlation coefficient between turnout and ENP is positive for Switzerland (see Appendix A2), from Figure 1 it is apparent that it is not true that turnout is rising with the increasing number of parties, although, within SMDs, turnout rises with increasing ENP. The stark non-linearity in the data is masked by a linear correlation. Moreover, for Spain the correlation between turnout and ENP is actually negative (see Appendix A2).

We can see more clearly what is going on when we distinguish between SMDs and districts of magnitude greater than 1, as shown in Figure 2. In both Spain and Switzerland, turnout rises with increased ENP in SMDs, but not in MMDs. In Spain, turnout actually falls with increased ENP in districts of magnitude greater than 1 . The results from a district fixed-effects regression reported in Table 1 show that the same significant negative relationship between turnout and ENP also holds within MMDs over time. ${ }^{9} \mathrm{~A}$ Hausman specification test of fixed versus random effects yields $\chi^{2}$ values of $2.71(p=$ 0.26 ) for Switzerland and $0.31(p=0.86)$ for Spain (with 2 d.f.), thus clearly indicating that there is no systematic difference in the turnout-ENP relationship within constituencies as ENP changes over time and that observed cross-sectionally across constituencies.

There are several other things that need to be said about Figures 1 and 2 that are important for understanding the Blais and Aarts (2006) puzzle. First, we observe that though both Spain and Switzerland have single-member districts, only in Switzerland do we find such districts with an effective number of parties less than two. Second, the average turnout is much higher in Spain than in Switzerland. Third, when we compare average turnout in districts with $m=1$ with turnout in districts with with $m>1$, we find a turnout of 0.38 for SMDs and 0.50 for MMDs in Switzerland, where a difference of means test yields a $t$-value of 7.99 with 241 d.f. and a $p$-value less than 0.01 ; while in Spain, mean turnout is 0.63 in SMDs and 0.74 in MMDs $(t=6.83,466$ d.f., $p<0.01)$. Fourth, in Switzerland, the only one of the two countries for which this is applicable, when we compare average turnout in SMDs with two or fewer parties with turnout in SMDs with more than two 


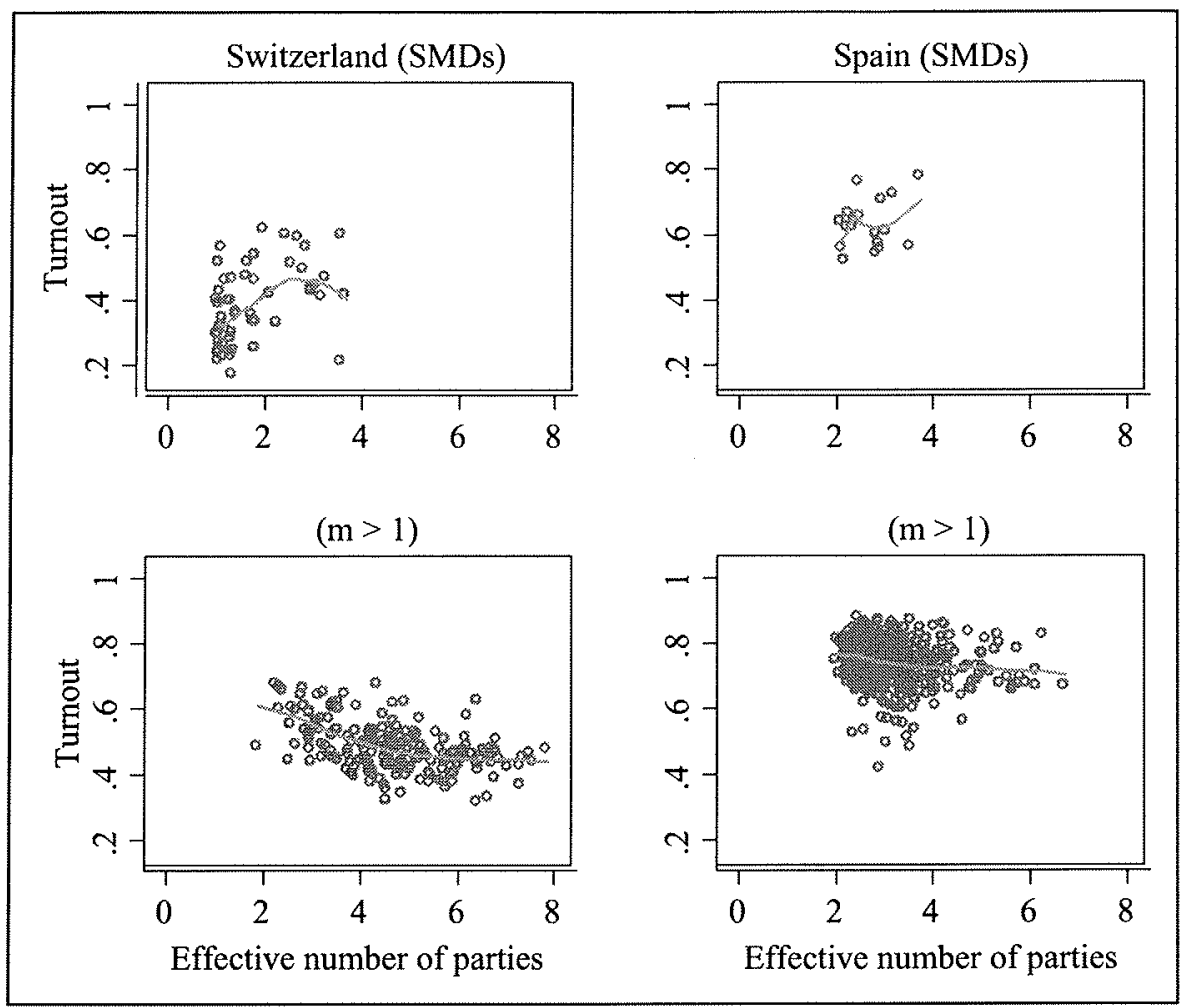

Figure 2. Turnout versus the effective number of parties (votes) in Swiss National Council elections, 1971-2007 ( $n=55$ for SMDs, 188 for MMDs) and in Spanish elections to the Lower Chamber, 1977-2004 ( $n=18$ for SMDs, 450 for MMDs). Lines represent locally weighted regression fit (LOWESS). Note: Compulsory voting district observations have been excluded

parties we find the former $(0.35)$ lower than the latter (0.46) to a statistically significant degree $(t=3.46,53$ d.f., $p<0.01)$. So, despite the absence of a positive relationship between turnout and ENP for the MMDs, turnout in the MMDs is higher than in the SMDs within both countries. Yet, only in SMDs is turnout higher as we move from constituencies with an ENP of 2 or less to ones with an ENP of 2 or more. Thus, we have a kind of step function. As we shift from plurality (generally speaking, low ENP) to PR (generally speaking, high ENP) elections, we get an increase in average turnout but, once we have made the shift, then ENP no longer matters for turnout.

Recognizing these latter calculations allows us to see why, ceteris paribus, we can expect to get a negative link between turnout and ENP using cross-national data, because for ENP $>2$ there may be a negative relationship between turnout and ENP, or as in Spain a virtually flat relationship. When we pool data from multiple countries, most of the data points will be from MMDs because there are considerably more countries using PR than using SMD-based electoral rules. Even if, within SMDs, there is a postive linkage, the MMD component of the relationship will be dominant and give us a negative linear slope (masking the non-linearities that we call attention to). Thus, if the withinnation patterns look like those of Switzerland and Spain, we expect to see a similar (primarily negative) pattern if we do cross-national aggregation.

While, for the reasons proposed by Jackman (1987), national differences in coalition structure tied to the number of parties in each country might help account for the lack of a 
Table I. Fixed-effects regression of turnout on ENP and a linear trend in districts with $m>1$. Clustered standard errors in parentheses.

\begin{tabular}{lclcl}
\hline Variables & Switzerland & & Spain & \\
\hline Effective no. of parties & -0.014 & $(0.005)^{* * *}$ & -0.015 & $(0.006)^{* * *}$ \\
Linear trend & -0.008 & $(0.002)^{* * *}$ & -0.002 & $(0.001)^{*}$ \\
Constant & 0.585 & $(0.023)^{* * * *}$ & 0.797 & $(0.022)^{* * * *}$ \\
SD due to districts & 0.050 & & 0.048 & \\
Residual SD & 0.047 & & 0.051 & \\
$\mathrm{R}^{2}$ (within) & 0.296 & & 0.018 & \\
$\mathrm{R}^{2}$ (between) & 0.325 & & 0.079 & \\
$\mathrm{~N}$ & 20 & 50 & \\
$\mathrm{~N} \times \mathrm{T}$ & 188 & & 450 & \\
\hline
\end{tabular}

$*_{p}<0.10 ; * * p<0.05 ; * * * p<0.01$

Note: Compulsory voting district observations have been excluded.

strong positive relationship between turnout and the effective number of parties in cross-national data, they cannot account for the lack of any positive district-level within-country differences in turnout across PR constituencies differing in their ENP. Thus, at this point, our new data analyses have only reinforced our sense of puzzlement.

In order to better understand the reasons for this turnout puzzle, we now seek to parse out the complex interactions between the (effective) number of parties based on voteshares and variables such as district magnitude, ${ }^{10}$ proportionality of seats-votes relationships, and political competition, which may play a direct or indirect role in stimulating turnout. We report in the Appendices means, variances and ranges for these key variables in each country, and also the bivariate correlations among these variables. "

One of our key variables is the Grofman and Selb (2009) index of political competition. Although many studies incorporate some measure of political competition, the assertion that PR systems are more competitive the larger the district magnitude and the larger the number of parties competing is problematic. Absent measures of political competition which are applicable and appropriate for both PR and SMD systems, such as those in Grofman and Selb (2009) and Blais and Lago (2009), the first of which we use here, in our view, this seemingly obvious claim has almost never been properly tested. ${ }^{12}$

The new and fully general index of political competition that we use here - which is based on a weighted average of party-specific, district-magnitude-specific and electoralsystem-specific features of the actual election outcomes - generates comparable measurement of political competition across districts of different magnitudes.

The Index of Competition is defined at two levels: at the party level, it equals the minimum (actual) district vote-share required for a party either to gain another seat or to lose its (final) seat, standardized by the Threshold of Exclusion of the district. Because we are standardizing in this fashion we are, in effect, controlling for differences in the electoral rules in use. At the district level, in turn, the Index of Competition is defined as the weighted sum of these party-specific Index values, where the parties' vote-shares provide the respective weights. Details of the calculation are given in the Appendix. 


\section{Explaining within-nation district-level differences in turnout}

We may think of explaining variations in turnout across different constituencies in terms of a series of interlinked propositions involving variables such as the (effective) number of parties, district magnitude and proportionality and political competition. Below, we state four propositions suggested by the theoretical arguments previously advanced in the literature on voter turnout:

(1) Ceteris paribus, the higher the district magnitude the higher the (effective) number of parties competing for votes.

(2) Ceteris paribus, the greater the political competition in a district, the higher the turnout.

(3) Ceteris paribus, the higher the (effective) number of parties competing for votes in a district, the greater the political competition in the district.

(4) Ceteris paribus, the higher the district magnitude, the greater the proportionality of electoral outcomes, and the lower the likelihood of wasted votes, and thus the higher the incentives for turnout.

If we take these propositions as specifying the conditions that structure crossconstituency differences in turnout, we can see that one of the key variables, district magnitude, will be connected to turnout through its impact on other variables such as proportionality or the number of parties or the effective number of parties. These variables in turn may have a direct impact, but much of their anticipated impact will be indirect - in terms of their consequences for political competition. Thus, we expect that political competition will be the variable with the most direct connection to district-level variations in turnout within a given country. ${ }^{13}$

However, while each of the bivariate relationships posited in the four hypotheses above is a theoretically plausible one, as we shall see, just as with the direct link between turnout and the effective number of parties, for one or both of the countries whose data we examine, some of these relationships simply are not what we expect. But, in each anomalous case, we will offer a theory-driven explanation of why the relationship may not be as straightforward as is most commonly supposed.

Let us take up each of the hypotheses in turn. We begin with Proposition (1), perhaps the least controversial of the set. We expect the (effective) number of parties to rise with an increase in district magnitude. And it is in large part because of the connection we expect between the number of parties and district magnitude (and the link we expect between district magnitude and incentives to turn out) that we are led to expect a link between the number of parties and turnout. So let us now look to see if Proposition (1) is satisfied when we look at data within Switzerland and Spain.

For Switzerland, the district-level evidence for Proposition (1), linking the (effective) number of parties competing for votes to district magnitude, is quite strong. Figure 3 shows the link between the (effective) number of parties competing for votes and district magnitude. Here, as expected, the (effective) number of parties competing for votes increases with district magnitude. But we would call attention to the fact that, as 


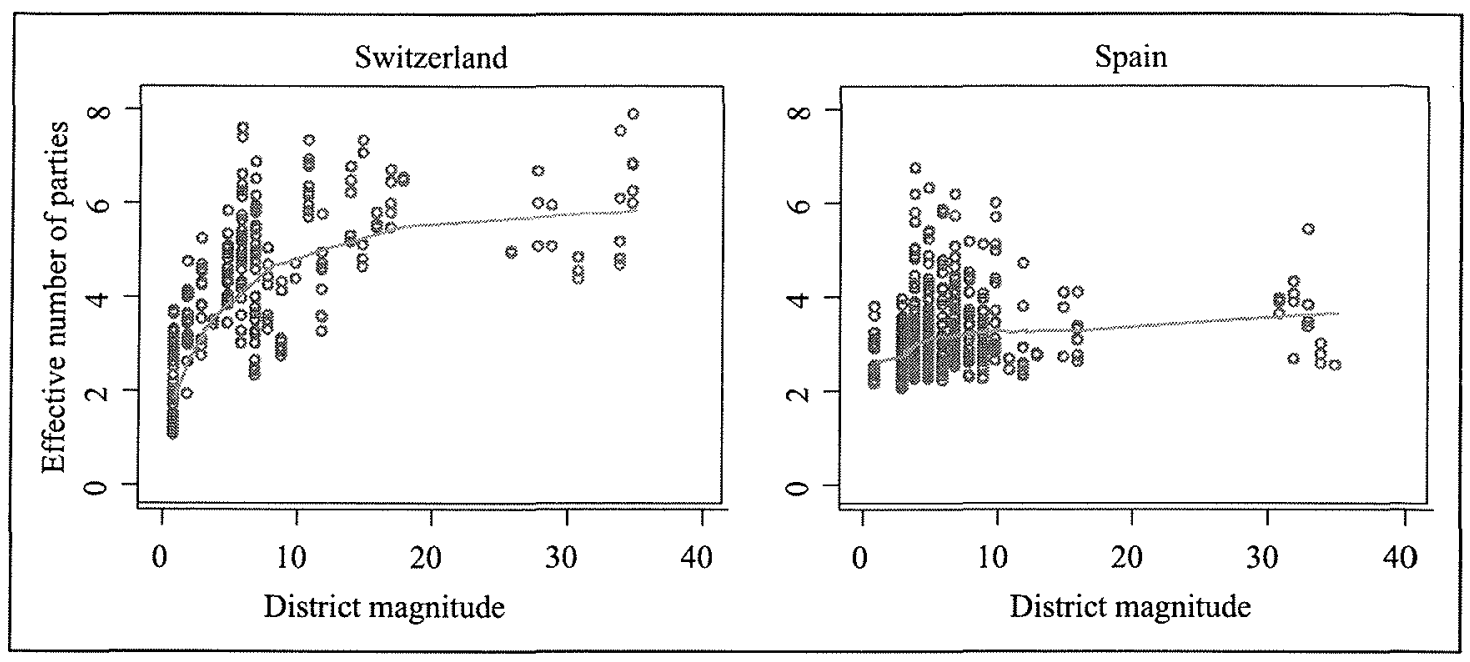

Figure 3. Effective number of parties (votes) versus district magnitude in Swiss National Council elections, 1971-2007 $(n=253)$ and in Spanish elections to the Lower Chamber, 1977-2004 $(n=468)$ for all districts. Lines represent locally weighted regression fit (LOWESS)

expected from the work of Taagpera and Shugart (1989), the relationship although monotonic is clearly non-linear. ${ }^{14}$

Turning to our next proposition, as we see from Figure 4, the evidence for Proposition (2), linking higher turnout in a district to the index of political competition in that district, is highly ambivalent. The relationship is found in Swiss SMDs but, for Swiss MMDs and for Spanish districts regardless of district magnitude, there is essentially no relationship between turnout and levels of competition.

We would also call attention to another aspect of Figure 4, namely that in Switzerland the range of variation in competition is much higher in SMDs than in MMDs, while in Spain both types of constituency tend to be relatively competitive. These countryspecific differences in patterns may, in part, be accounted for by the fact that, as we noted earlier, overall turnout is much higher in Spain than in Switzerland. The very high turnout rates in Spain imply that it is going to be harder to get large cross-constituency turnout variations since we are dealing with constraints on the differences that are mathematically possible, that is, it is difficult to get huge variation across districts in turnout and still end up with a high overall turnout. In Switzerland, overall turnout is at a level where there can, in principle, be huge turnout differences across districts (c.f. Grofman, 2009).

So far we have shown that for our district-level data, unlike what common sense (and rational choice theories) would lead us to expect, neither higher levels of competition nor the greater number of parties with which such competition is supposed to be associated always give rise to higher turnout. Neither expectation is satisfied in Spain, and the second expectation is not satisfied in Switzerland once we restrict ourselves to districts with magnitude greater than 1. Now we turn to a test of Proposition (3), that the higher the number of parties competing for votes in a district, the greater the political competition in a district. If that proposition also fails for one or both of our countries, then we begin to suspect that some key elements of the theoretical edifice often used to predict turnout 


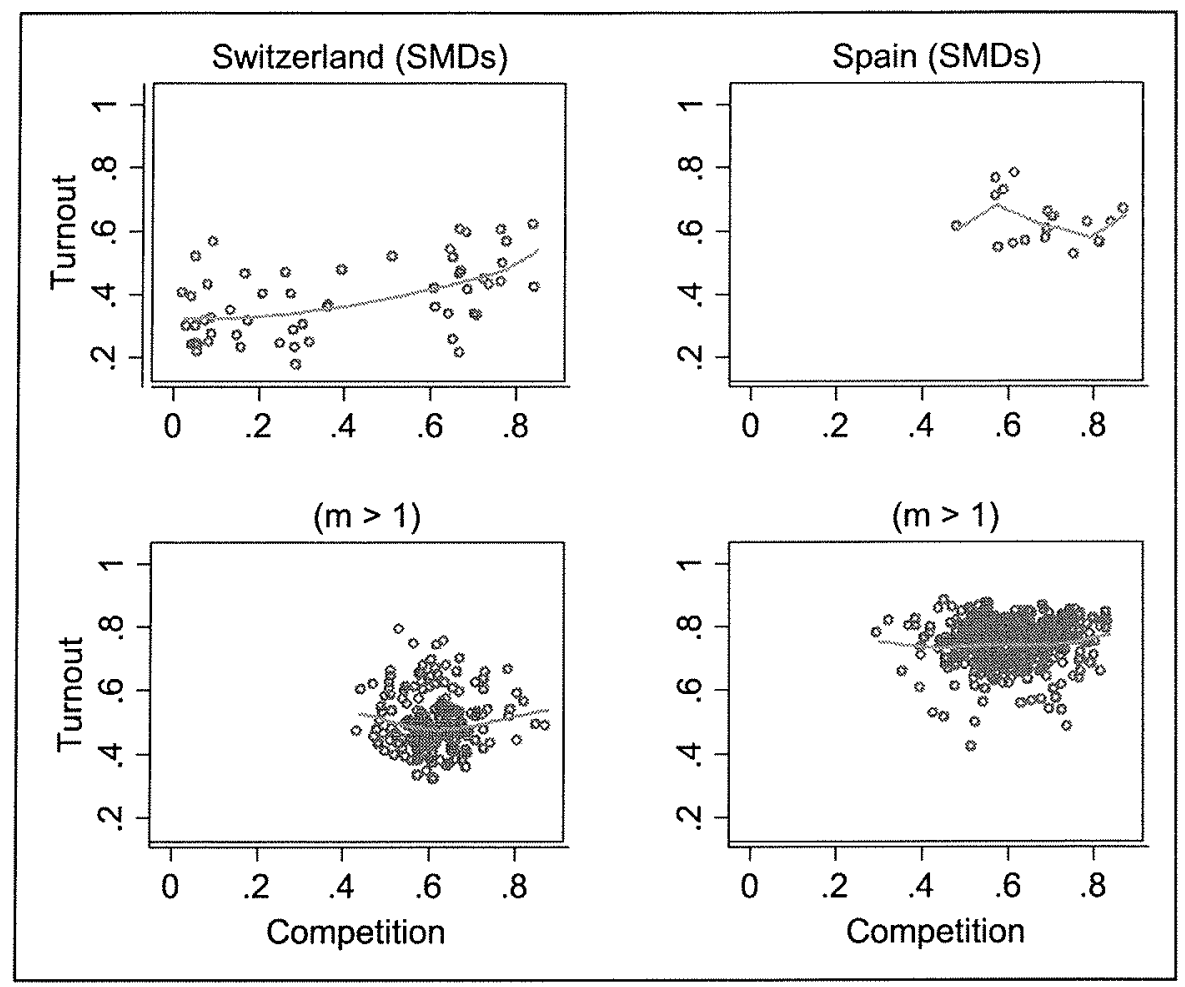

Figure 4. Turnout versus Index of Competition in Swiss National Council elections, 1971-2007 ( $n=55$ for SMDs, 188 for MMDs) and in Spanish elections to the Lower Chamber, 1977-2004 ( $n=18$ for SMDs, 450 for MMDs). Lines represent locally weighted regression fit (LOWESS). Note: Compulsory voting district observations have been excluded

variations across types of electoral rules and party systems may be erected in large part on sand, however well they work when we restrict ourselves to the single-seat context. ${ }^{15}$

The evidence for Proposition (3), linking the (effective) number of political parties in a district to political competition in a district, is also inconsistent. While the correlation coefficient is positive in Switzerland, 0.45 (see Appendix A2), we can see from Figure 5 that (as with Figure 1) the Swiss pattern is once again non-monotonic. In particular, political competition declines with ENP once we reach districts with more than two effective parties. ${ }^{16}$ Indeed, when we restrict ourselves to a district magnitude greater than 1 , the correlation coefficient changes sign in Switzerland to - 0.23. In Spain, the pattern is different still: with a slight negative relationship within the SMDs and no relationship for MMDs and with an overall correlation close to zero (see Appendix 2).

Before we go on to consider the empirical evidence for Proposition (4), this is a useful place to step back from the empirical evidence and go back to theory to try to understand why more parties might not be associated with increased political competition.

The key point to make is that there really is no reason to expect a linear relationship between the number of parties and competition.

For single-seat districts, the Index of Competition reduces to the gap between the winning party and the largest losing party. When the combined vote-shares of the top two parties are large (as they are in many SMD contests), as the gap between them narrows, most voters have a stronger incentive to vote. Thus for SMDs with something close to 


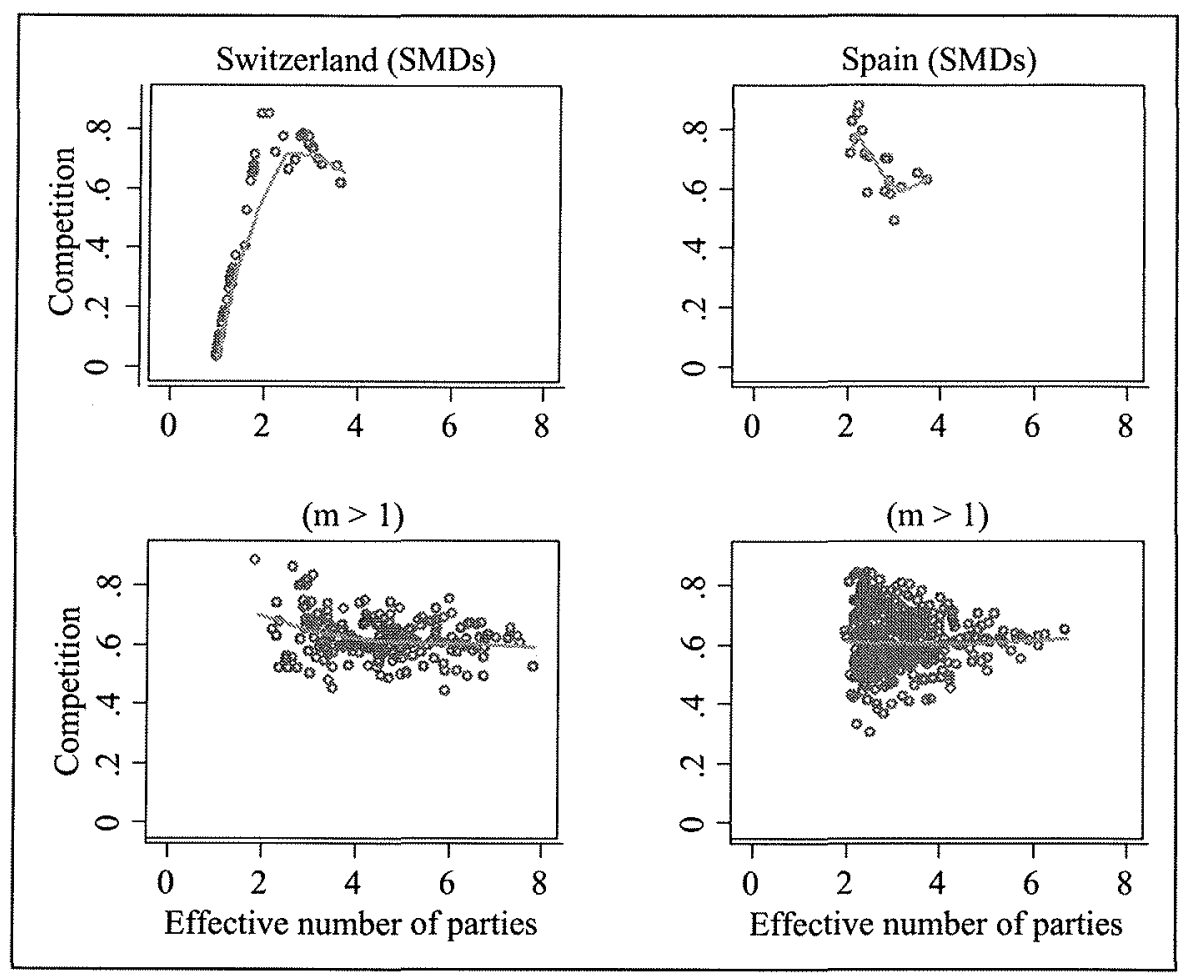

Figure 5. Index of Competition versus the effective number of parties (votes) in Swiss National Council elections, 1971-2007 ( $n=55$ for SMDs, 198 for MMDs) and in Spanish elections to the Lower Chamber, 1977-2004 ( $n=18$ for SMDs, 450 for MMDs). Lines represent locally weighted regression fit (LOWESS)

two-party competition we do expect a positive relationship between turnout and political competition, and this is exactly what we find in the one of our two countries for which relevant evidence is available, namely Switzerland. ${ }^{17}$ However, if there are lots of political parties in an SMD contest, there are few constraints on what level of competition we might expect. So, for SMDs whether turnout can be expected to rise or fall with an increase in the effective number of parties depends upon the exact shape of the voter distribution.

But there is also no good reason to expect a large number of parties to be associated with higher levels of competition in MMDs. Once we look at turnout incentives in partyspecific fashion, as required by the Grofman-Selb Index of Competition, it is easy to construct examples of multiparty settings where turnout incentives will not be that great because only relatively major changes in votes will change seat allocations. Consider, for example, the four-seat distribution $(0.45,0.30,0.20,0.05)$. Under d'Hondt, we will get an allocation of $(2,1,1,0)$. But for party $A$ to lose its second seat, party $A$ would need to lose a minimum of 7.5 percentage points of vote-share, all of which would have to go to party B for such a loss to matter. For party B to lose its seat it would need to lose a full 11.25 percentage points. For party $\mathrm{C}$ to lose a seat it would need to lose at least 3.3 percentage points, all of which would have to go to party A for such a loss to matter. For party $\mathrm{D}$ to be sure to gain a seat it would need to pick up a full 15 percentage points. 
Thus, the Index of Competition is $0.45^{*}(12.5 / 20)+0.30 *(9.75 / 20)+0.20 *(16.7 / 20)+$ $0.05^{*}(5 / 20)=0.61$, which is a rather low value of the Index.

Another reason why the link between the effective number of parties and political competition will probably not be that strong for $m>1$ is that the Laakso-Taagepera index does not go up much if we further fractionate already small parties. If an increase in district magnitude allows more small parties to get seats, but most of the votes still go to major parties, then the changes in the effective number of parties as we increase $m$ may be minimal. Indeed, we have seen from Figure 3 that the effective number of parties rises only slowly with district magnitude. Similarly, if the increased incentives for turnout as we increase $m$ are mostly going to (potential) new voters for these small parties (parties perhaps on the fringes of the political system), then the overall impact on political competition (as it is measured here) will also be minimal, simply because there are not that many such voters. On the other hand, the contributions of these additional small parties to our party-support-weighted competition index is likely to be negative, since the instrumental incentive for their supporters to vote may not be large, since these parties' chances of gaining a seat may also be minuscule. ${ }^{18}$

Also, some authors have argued that the existence of many parties may complicate choices and therefore raise the information costs of electoral participation (e.g. Brockington, 2004; Geys and Heyndels, 2006). While this argument might appear to have its greatest force at the national level it can also apply at the district level.

The point argued above, that at the district level there are sound theoretical reasons why we should not expect competition necessarily to go up with the increased number of parties, is further strengthened by looking directly at the link between competition and district magnitude, as shown in Figure 6. We have already seen that the level of competition does not increase with the effective number of political parties, at least once we get above two parties. From the left panel of Figure 6 we can see that, in Switzerland, the level of competition does not increase with increasing district magnitude once we get beyond single-seat constituencies. (Note: we again need to be careful actually to look at the figure rather than rely on the linear correlation coefficient reported in Table A2[a], since the pattern in non-monotonic.) From the right panel of Figure 6 we see that, in Spain, the sign of the relationship between competition and district magnitude is actually slightly negative. Higher magnitude districts are actually less competitive.

But even if political competition is not efficacious in creating a link between more parties and more turnout, should we not see a pattern of turnout gain as we increase district magnitude, since we are increasing proportionality and reducing wasted votes? We now turn to an examination of Proposition (4).

Figure 7 shows the relationship between proportionality (the Loosemore-Hanby index) and district magnitude for Switzerland and for Spain. Figure 8 shows the relationship between turnout and district magnitude for Switzerland and for Spain.

What we find in Figure 7 is that disproportionality goes down with increasing district magnitude, although at a diminishing rate. What we find from Figure 8 , however, is that turnout does not increase with district magnitude. Once we pass the $m>2$ threshold, in both countries the relationship is essentially flat. To better understand why we might get this rather puzzling result, in clear violation of the expectation stated in Proportion (4), we provide two further figures. Figure 9 shows the relationship between proportionality 


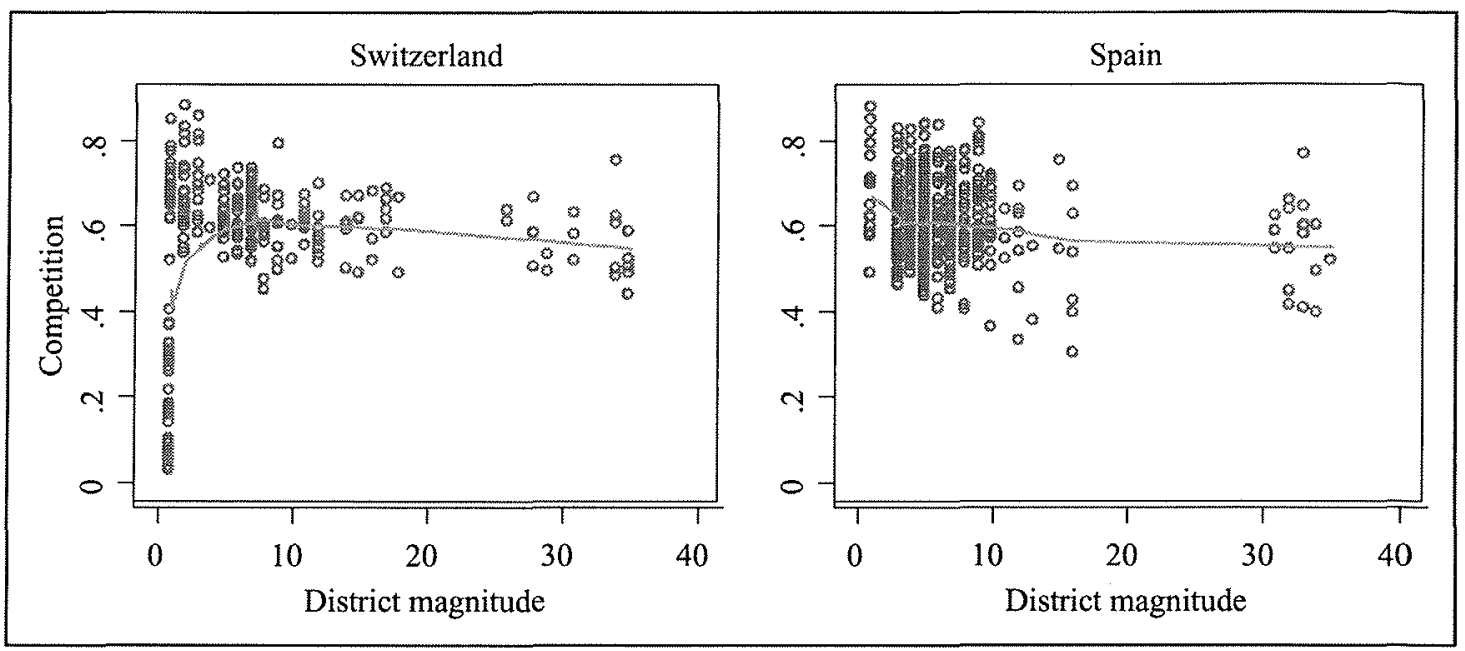

Figure 6. Index of Competition versus district magnitude in Swiss National Council elections, 1971-2007 $(n=253)$, and in Spanish elections to the Lower Chamber, 1977-2004 $(n=468)$ for all districts. Lines represent locally weighted regression fit (LOWESS)

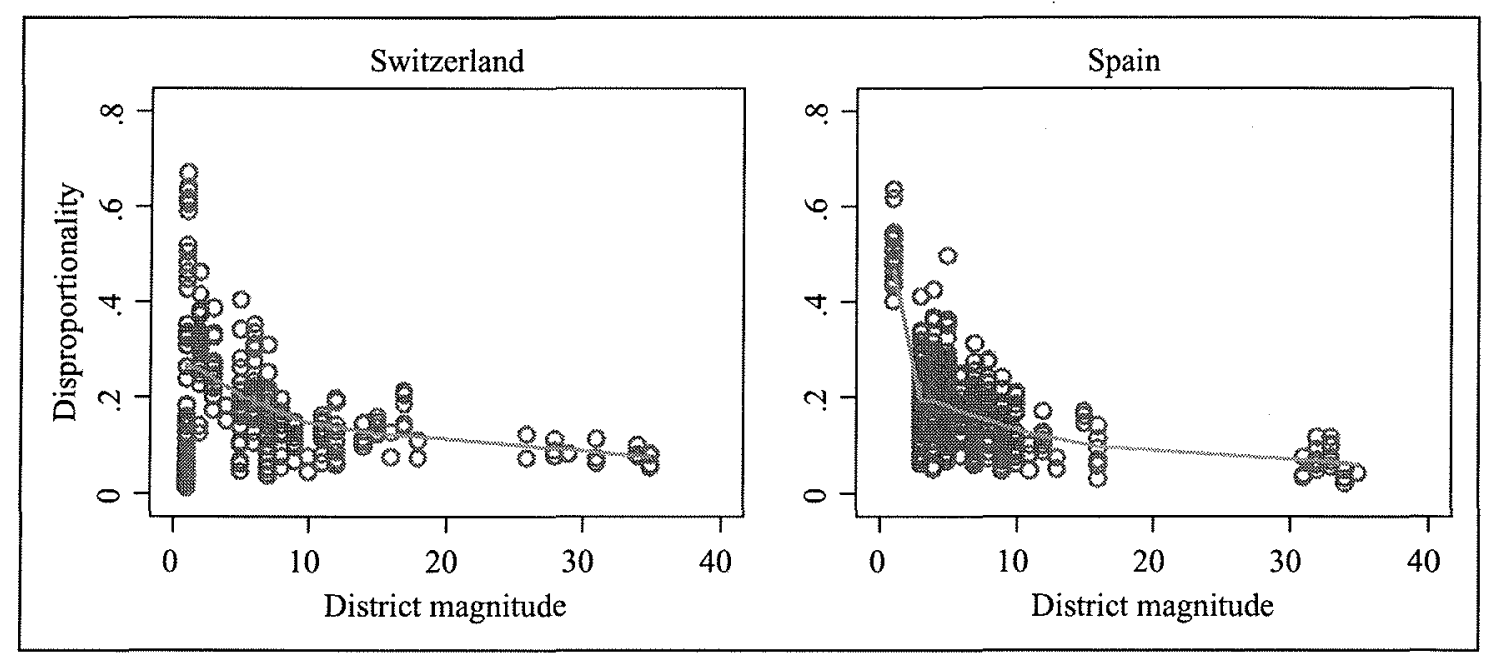

Figure 7. Index of Disproportionality versus district magnitude in Swiss National Council elections, 197I-2007 $(n=253)$, and in Spanish elections to the Lower Chamber, 1977-2004 $(n=468)$ for all districts. Lines represent locally weighted regression fit (LOWESS)

and ENP. Figure 10 shows the relationship between proportionality and our Index of Competition, with data broken down into SMDs and MMDs.

From Figure 9 showing the relationship between proportionality and ENP we can see that larger numbers of effective parties tend to produce less proportional election results, although this relationship is stronger in SMDs than in MMDs. This within-nation finding is similar to the Taagepera (2007: 68, Figure 5.1) finding for cross-national data. They find that disproportionality goes up with ENP within SMDs, but is essentially flat (or even slightly down) within MMDs.

The reason they give for the PR case is a simple one: higher $m$ induces more parties to enter, and this leads to more wasted votes. The incentive effects of $m$ on party 


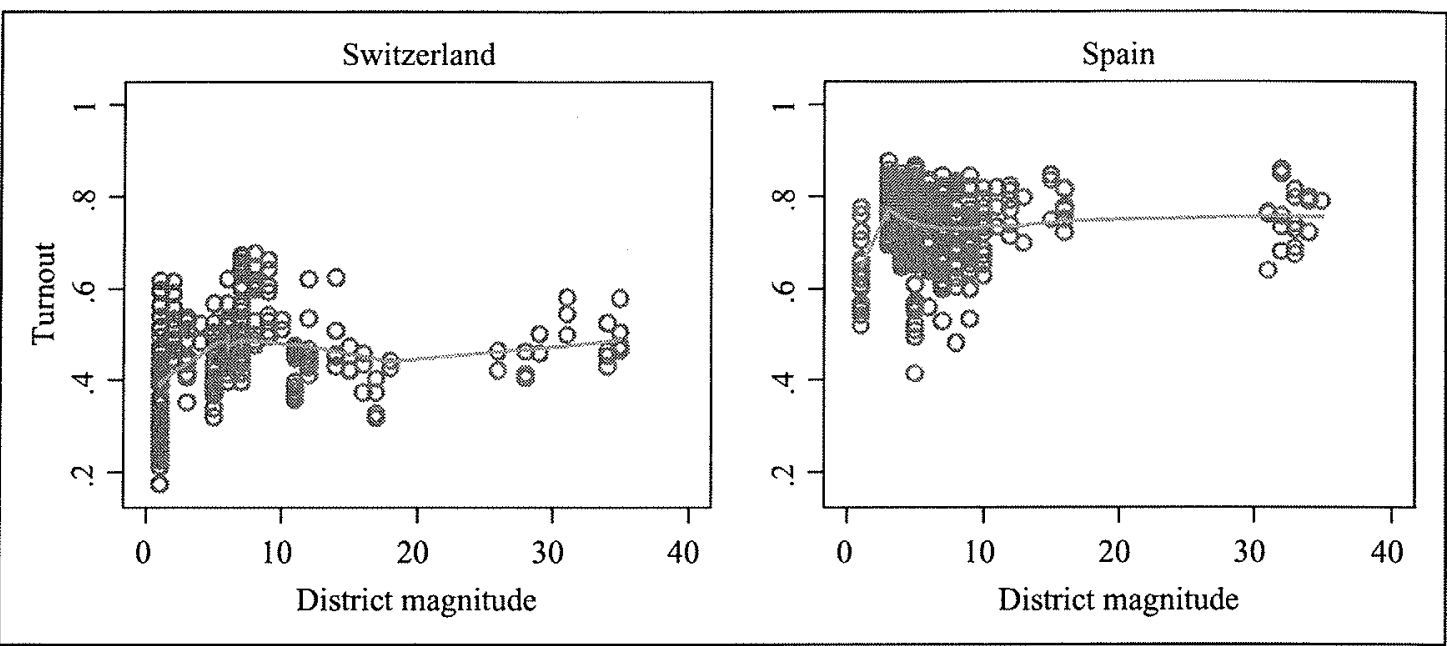

Figure 8. Turnout versus district magnitude in Swiss National Council elections, 1971-2007 $(n=$ $243)$, and in Spanish elections to the Lower Chamber, 1977-2004 $(n=468)$ for all districts. Lines represent locally weighted regression fit (LOWESS). Note: Compulsory voting district observations have been excluded

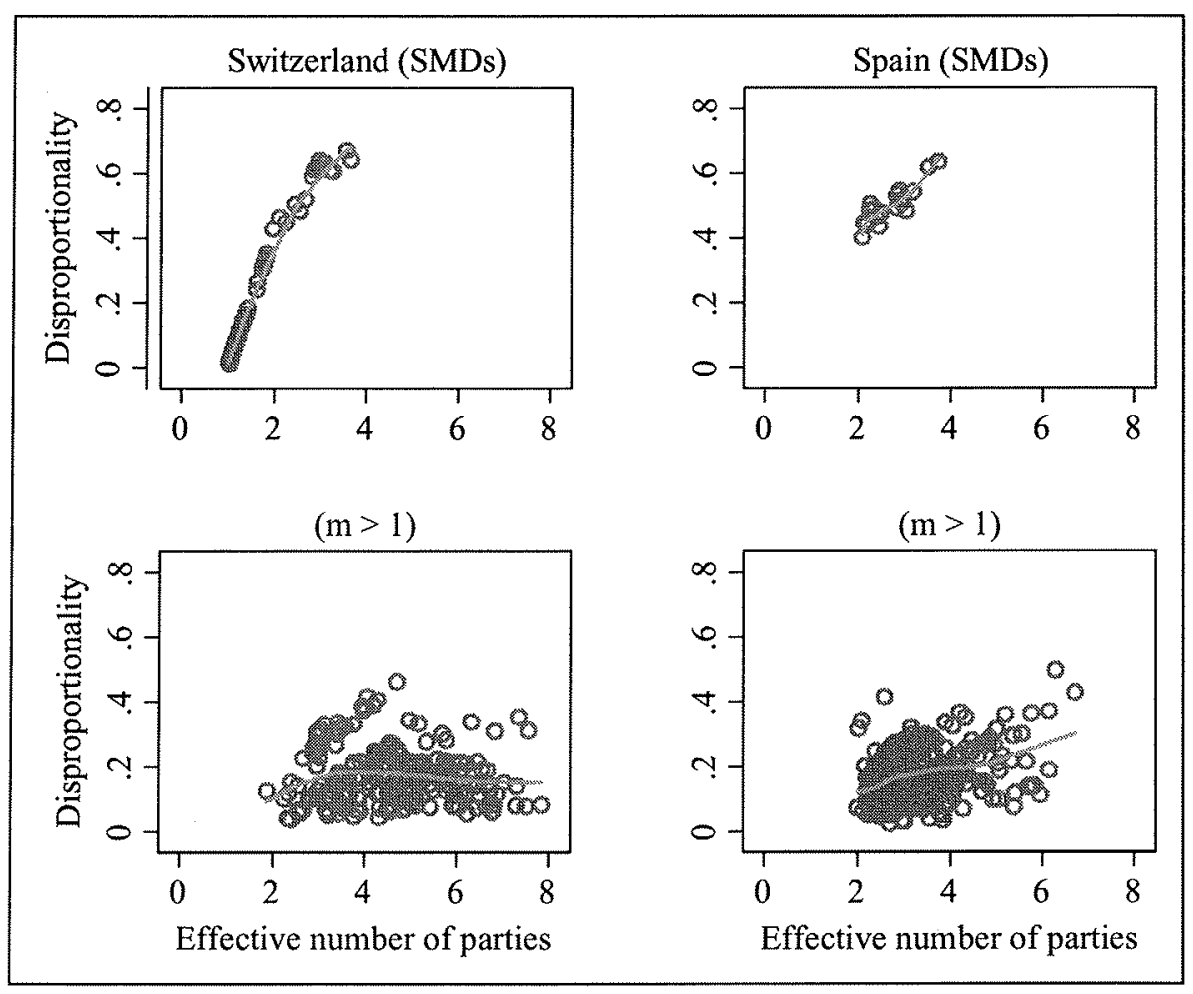

Figure 9. Disproportionality versus the effective number of parties (votes) in Swiss National Council elections, I97I-2007 ( $n=55$ for SMDs, 198 for MMDs) and in Spanish elections to the Lower Chamber, 1977-2004 ( $n=18$ for SMDs, 450 for MMDs). Lines represent locally weighted regression fit (LOWESS)

proliferation work against the effects of $m$ in increasing proportionality, so that the relationship of $m$ with proportionality is nearly flat. For plurality elections, on the other hand, disproportionality may rise with the number of parties because there are lots of 


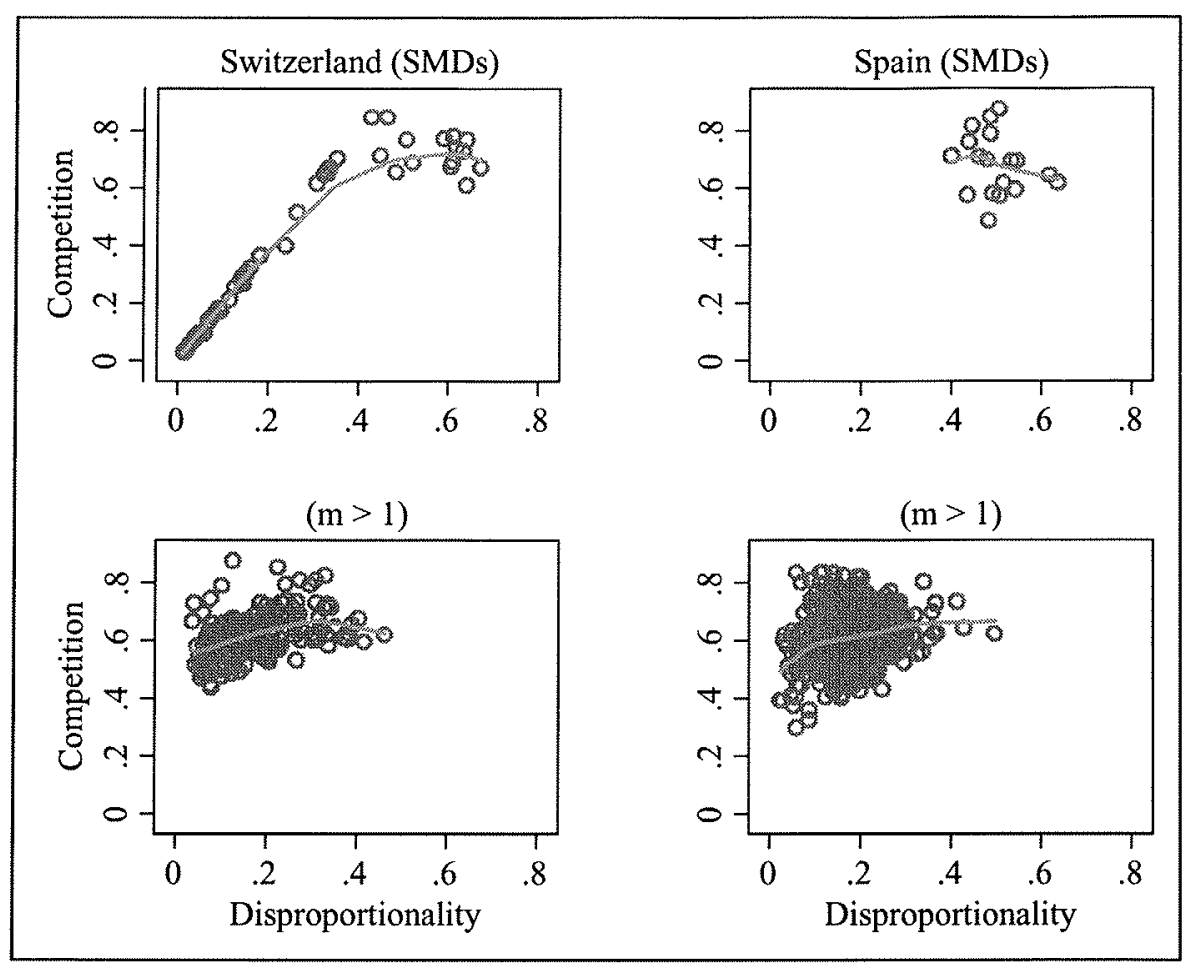

Figure 10. Competition versus Disproportionality in Swiss National Council elections, 1971-2007 ( $n=55$ for SMDs, 198 for MMDs) and in Spanish elections to the Lower Chamber, $1977-2004$ ( $n=18$ for SMDs, 450 for MMDs). Lines represent locally weighted regression fit (LOWESS)

small parties which gain no seats, and the winning party may not have a majority. But if proportionality does not rise with $m$, the supposed link between the number of parties and a lower percentage of wasted votes becomes highly suspect. The higher the number of candidates, the higher the potential for coordination failures leading to disproportionality. And, indeed, when we look at the relationships shown in Figure 9 between proportionality and district magnitude, as with the relationship between turnout and the effective number of parties, we simply do not get the positive link that we might once have thought we ought to find.

As for Figure 10, the relationship between proportionality and our Index of Competition is negative, that is, the relationship between disproportionality and our Index of Competition is positive, except for the most competitive seats in the SMDs. Thus, just as competition does not increase with $m$, neither does proportionality, and the two effects are (except for very highly competitive SMDs) going in the same direction.

In sum, the two key forces that are usually supposed to lead to an increased turnout as we increase district magnitude, namely greater proportionality and greater competitiveness, simply do not function this way! Neither is positively linked to increased district magnitude, and thus there is essentially no reason to expect either to be positively linked to the increased ENP that also comes with increased district magnitude.

Also, while our data do not allow us to address this question directly, the often claimed link between greater range of ideological choice in MMDs as we increase district magnitude and greater incentives for turnout is not that clear. For a relatively stable 
party system, and for $m$ fixed, it is easy for parties, especially in a PR system, to 'get in a rut' holding on to the seats they have in any given constituency but not really making great efforts to go beyond their present base. A thought experiment is useful. Imagine an MMD constituency with a large number of parties. These parties are likely to have established 'niches' for themselves that will largely insulate them from competition except from parties that are ideologically proximate. And if they are 'boxed in' by other parties, their ability to find a vote-maximizing strategy is limited (cf. Adams et al., 2005). We can even have volatility in vote-shares without much change in seat distributions. The limited incentives to turn out based on the competitive struggle for seats in MMDs is futher exacerbated when we have multiple small parties with little or no chance of gaining seats competing largely for expressive reasons.

Our last and related point vis-à-vis the lack of relationship between ENP and competition or turnout is to call attention to the work of Geys and Heyndels (2006), which suggests a different and potentially promising direction to go in seeking to gain traction on the puzzles that are at the heart of the work of Blais and Aarts (2006) and this article. They suggest that we need to distinguish two different dimensions of fragmentation, which are related to but yet distinct from the effective number of parties: one based on the raw number of electoral parties and one based on the variation in size among the parties. Using data on Flemish local elections, they show that the effects of these two components go in different directions. They find turnout to fall with increases in the raw number of parties, but to increase the more unequal in size the parties are.

We have replicated their idea for both Swiss and Spanish data (data omitted for space reasons). Our results from these two countries replicate their finding for Flemish data: the raw number of electoral parties is negatively linked to turnout and I, inequality in party sizes, ${ }^{19}$ is positively linked to turnout. However, as with the data reported earlier, there are important differences between the Spanish and Swiss cases. Also, Geys and Heyndels do not offer any compelling reasons for why their index I should have the impact they (and we) find.

As for the differences we found between Spain and Switzerland in terms of relationships linked to turnout, we have already alluded to the differences in mean turnout between the two countries as one factor that may explain some of the differences, but there are other aspects of political competition in the two countries to which we wish to call attention in line with the notion that electoral systems are 'embedded institutions' ${ }^{20}$ For present purposes, there are two aspects of this embeddedness we wish to emphasize.

First, there is the existence of simultaneous elections which neither use identical rules nor have identical district magnitudes. Choices made by parties and voters in one election can have spillover consequences for the other. Taking this parallelism into account, we may discover that neither election behaves fully in accord with the expectations based on its pure type. ${ }^{21}$ Second, we have the role of political parties and deals that may be made among them. For example, in French legislative elections in the Fifth Republic, members of a given tendance may agree to withdraw from the second round of a two-round election in favour of a candidate of another party from that same tendance who received a higher vote-share on the first round (Tsebelis, 1988). Here, the parties coordinate in order to avoid the worst outcome of a victory by a member of another tendance. 
In both Switzerland and Spain there are contaminating effects from the presence of other simultaneous elections whose effects are coupled with important consequences of elite bargaining. In Switzerland, political parties from time to time parcel out National Council and Council of States seats (the Federal chamber; simultaneously elected in most districts, two seats per district, absolute majority required) before an election. In these instances, elections are mock elections, since there is no serious challenger competing. ${ }^{22}$ The informal agreement on the government composition: (1) disengages voters and parties directly from participating and mobilizing in elections, and (2) disengages the parliament from building stable majorities in order to form government coalitions. Therefore, in Switzerland, more parties do not carry the risk of failure in government formation. The differences between Switzerland and Spain in the nature of the government coalition processes may help account for differences between the two countries in the patterns we observed.

In Spain, Congressional (districted PR) and Senate (limited vote in four-, three-, twoand single-member districts) elections are held simultaneously, and provide similar incentives to negotiate in small districts and, perhaps even more importantly, tend to smooth out political competition in terms of the effective number of parties competing in districts of different magnitudes (see Lago and Martinez, 2007: esp. Table 2). ${ }^{23}$

\section{Discussion}

Using district-level data for both Spain and Switzerland, we have shown that higher ENP does not imply higher political turnout. These findings allow us straightforwardly to explain our initial puzzle of why there is not a strong relationship cross-nationally between the effective number of political parties and turnout by showing the absence of a districtlevel link between the effective number of political parties and political competition in any country (at least for districts with more than two effective parties or in districts of magnitudes greater than 1). Thus, our country-specific findings allow us to explain the nationallevel puzzle as essentially an ecological artefact, in that the MMD districts found in PR systems, on average, do exhibit higher turnout than SMDs, but turnout does not necessarily rise with $m$, once we move beyond the contrast between $m=1$ and $m>1$.

To explain the new country-specific puzzle about the link between the number of parties and turnout that we were now left with, we looked at a set of four propositions that are often used to create a causal chain linking the effective number of parties to turnout. When we did so we found that three of the four links in this chain were flawed empirically. For example, just as Taagepera (Taagepera, 2007; Taagepera and Shugart, 1989) showed with cross-national data that disproportionality does not necessarily decrease in PR systems as the number of parties increases, we showed the same pattern when we looked at within-nation variation in disproportionality.

Then we looked at the theoretical bases of the claim that ENP should be positively linked to turnout. Here, we built on the Taagepera argument about coordination failure to explain why proportionality need not rise with increasing district magnitude in PR systems, and we used an example based on the Grofman-Selb (2009) Index of Competiton to demonstrate why, for PR systems, competition does not necessarily increase with the number of parties. In sum, we were able to show that two key arguments commonly 
given for why incentives for turnout in PR systems should rise with the number of parties, namely greater proportionality that reduces wasted votes and greater competitiveness as we increase the number of parties, simply do not work, either empirically or theoretically, in the straightforward way that they are often supposed to.

We make no claim that ours is the last word on the puzzle of why turnout is higher in PR systems than under other electoral rules and yet turnout does not rise with an increasing number of parties. But we do believe that our within-nation empirical findings and theoretical reasoning about the flaws in two key propositions underlying the expectation that more parties would increase turnout - linked to proportionality and to competitiveness, respectively - take us considerable steps in a puzzle-solving direction. ${ }^{24}$

\section{Acknowledgments}

The listing of author names is alphabetical. We are indebted to Sue Ludeman for bibliographic assistance. The first named author's contribution to this research was supported by the Jack W. Peltason (Bren Foundation) Endowed Chair, by the Center for the Study of Democracy, University of California, Irvine, and under Social Sciences and Humanities Research Council of Canada (SSHRCC) Grant \#410-2007-2153, to study 'Political Competition' (co-PIs: Stanley Winer, and J. Stephen Ferris).

\section{Notes}

1. Table 2 in Blais and Aarts (2006) reviews six (1990 or later) cross-national studies of the link between electoral system types (measured by disproportionality) and turnout. All show the expected positive link. However, the two largest $n$ studies, which are also the ones with the most extensive set of control variables (Blais and Dobrzynska, 1998), find relatively limited differences in turnout due to electoral system effects once other factors are controlled for. Their own overall present estimate of the impact of PR is 'in the vicinity of 3 to 5 points', which they describe as 'neither huge nor tiny' (Blais and Aarts, 2006: 7).

2. The notion that the range of choice is greater in PR systems is based in part on the classic Downsian view that political competition in SMD plurality systems is usually of a tweedledum-tweedledee nature. But that theoretical claim is contradicted by the empirical evidence. Moreover, the tweedeldum-tweedledee claim for two-party competition under plurality is not even that well supported theoretically once we recognize that the asumptions of the Downsian model are often violated in real-world elections, for example, in situations where candidates are chosen on the basis of partisan primaries (Grofman, 2004).

3. Relatedly, since PR systems allow for parties to win office with less than a majority (or even plurality) of the votes cast within a constituency, and also allow parties to win more than one seat if their voting support is large enough, it might appear that there should be fewer 'losers' votes' under PR than under plurality, that is, fewer voters who cast their vote for a party in their district that failed to win at least one seat. In so far as success in electing a candidate of one's choice is reinforcement for voter turnout, PR elections thus should be able to sustain higher levels of turnout than SMD plurality elections. In so far as there are fewer voters in PR settings who are likely to see their vote as wasted, this should lead to higher turnout in the PR setting. Of course, if we restrict ourselves to single-seat constituencies, the wasted-vote argument might actually suggest higher turnout in safe seats, since there are fewer voters who are perpetually frustrated by an inability to vote for a winner. 
4. See especially Brockington (2004).The only exceptions are studies limited to Latin America, but Blais and Aarts (2006) do not attach high value to these studies because of a limited range in the independent variable.

5. In such systems of 'districted PR' (Monroe and Rose, 2002), district magnitude is largely a function of the size of the local electorates. Therefore, district magnitude may be empirically linked to other potential antecedents of turnout and party system size, such as socio-economic modernization or urbanization (also see last note).

6. We do, however, need to be careful in any comparisons of ENP between Spain and Switzerland, since the Swiss data lump very small parties, while the Spanish data do not. The way in which the Swiss data are reported does not allow us to correct for incomplete party-share data in the way suggested by Taagepera (1997).

7. See, however, Blais and Carty (1990) and Blais and Dobrzynska (1998), who do not find higher turnout in elections involving single-party governments when other factors are controlled.

8. Relatedly, Huber et al. (2005) find a strong negative relation between the effective number of parliamentary parties and the propensity to identify with a party.

9. We have also included a linear trend in order to account for a secular turnout decline observable in both countries, although considerably more pronounced in Switzerland. The inclusion of a linear trend has reduced the serial correlation of the residuals to a negligible magnitude.

10. District magnitude is linked to proportionality in different ways for different electoral systems, via the Threshold of Exclusion (and the Threshold of Representation). But, for any given electoral rule, the Threshold of Exclusion is an inverse function of district magnitude (see Lijphart and Gibberd, 1977).

11. Of course, purely bivariate relationships must always be examined with care given the potential for interaction effects and the need for properly specified models.

12. Franklin (2004) uses mean margins of victory across districts in majoritarian systems but codes this variable 0 for all PR systems. Thus, he treats all PR systems as identical with respect to this variable. Franklin finds that this measure displaces the effect of the PR system variable in a multivariate analysis of national turnout. Blais and Lago (forthcoming) generate a turnout incentive measure similar to our own save for the fact that it is only district-specific and not party-specific.

13. Looking at bivariate correlations, we find competition to be the best single predictor of turnout (see Appendix).

14. In Switzerland, as we see from Figure 5, the relationship is clearly non-linear. This is consistent with expectations based on the seminal statistical work of Taagepera and his co-authors (e.g. Taagepera and Shugart, 1989) that the number of parties will rise as an exponential function of $m$, but with an exponent less than 1 . It is also consistent with the notion that the (effective) number of political parties cannot be expected to increase indefinitely in that the number of parties will be a function of both electoral institutions and ethnic and political cleavage structures. As Lago and Martinez (2007) summarize this literature: '[L]ow heterogeneity imposes an upper bound on the number of parties, even in the presence of a very permissive electoral system, because there is no need or demand for many parties. Similarly, a strong electoral system (i.e. low district magnitudes) limits the number of parties, even if a polity has many cleavages, because there are poor opportunities to create many parties (i.e. political entrepreneurs do not have incentives to base separate parties on these cleavages). Therefore, 
a polity will have many parties only if it both has many cleavages and a permissive electoral system' (c.f. Amorim Neto and Cox, 1997).

15. We say 'may be' because we recognize that bivariate relationships may reverse in a better specified multivariate model.

16. Moreover, we do need to be careful in distinguishing empirical from analytic linkages. It is well known that the effective number of parties is a reciprocal measure of concentration. In a single-member district with only two competitors, having more effective parties (i.e. less vote concentration) and having more competition are just two ways of saying the same thing.

17. See also the review of studies of turnout in United States presidential contests in Foster (1984), but also see the discussion of methodological pitfalls in analysing the link between turnout and political competition in Grofman et al. (1995).

18. Another possible reason why we do not observe competition increasing with either district magnitude or the effective number of parties is that, as Grofman (2001a) reminds us, increases in district magnitude also create more populous districts, with population rising roughly linearly with $m$. The Index of Competition we use in this article controls for this fact. If, however, parties think of the competitiveness of a district not in terms of what vote-share is needed to gain or lose a seat, but in terms of the number of raw votes that are needed, then competitiveness (as measured here) may not go up as $m$ increases. Grofman and Selb (2009) also present an alternative index of competition that is not normalized by the threshold of exclusion. When, as above, we normalize, it is assumed that for national parties it does not make a difference whether they have to mobilize, say, 1000 additional voters in an SMD $(\sim 30$ percent of the electorate) or 1000 additional voters in a district with three seats $(\sim 10$ percent of the electorate). If it is local party organizations that do the mobilizing and we posit that their mobilization capacity is roughly proportional to the size of the electorate in the constituency, mobilization incentives should be three times higher in the three-member district, that is, competition will rise, on average, with increasing district magnitude.

19. The inequality in party sizes is defined as:

$$
i=1+\left(\frac{1}{N} \sum_{i=1}^{N}\left(v_{i}-\bar{v}\right)^{2}\right)^{.5} / \bar{v}
$$

where $N$ is the raw number of parties and $v$ is the vote-share of party $i$ (see Geys and Heyndels, 2006: 381).

20. For an introduction to an embedded systems perspective on electoral rules, see the editors' introductions to Grofman et al. (1999) and Bowler and Grofman (2000).

21. The most important literature on such contamination effects is that dealing with mixed electoral systems (e.g. Cox and Schoppa, 2002; Herron and Nishikawa, 2001), but the same idea applies far more broadly (see e.g. Lago and Martinez, 2007; Moenius and Kasuya, 2004).

22. Some districts explicitly provide for the opportunity of 'tacit elections', that is, no elections in these instances. In districts where there is no official deadline for the nomination of candidates, however, the election has to be held. It is amazing how many protest votes exotic candidates can gain from time to time in such elections with seemingly foregone outcomes. 
23. There is, however, one important difference in the patterns in the two countries: extremely low levels of competition in some SMDs in Switzerland result from local-level elite agreements, but there does not seem to be such extremely non-competitive seats in Spain, perhaps because the main parties are more directly rivalrous there as opposed to the consensual governance style in Switzerland.

24. One potentially promising direction, called to our attention by one of the anonymous referees, is to look at urbanization. Districts with high values of $m$ may be disproportionately urban, and we expect turnout differences across levels of urbanization. We have explored multiple regression models including urbanization along with ENP, but urbanization was not statistically significant. We would also note that linear regression results can be misleading given the critical non-linearities we have found in the data.

\section{Appendix I. Calculation of the Index of Competition according to Grofman and Selb (2009)}

Here, we detail the calculation of the Index of Competition for the d'Hondt formula of seat allocation, since this is the method that is applied in Spanish Congressional elections. The Hagenbach-Bischoff method used in Swiss National Council elections is equivalent to d'Hondt (see Gauglhofer, 1988). Analogous results can be generated for other parametric divisor rules such as Sainte-Laguë or the Danish method. Under d'Hondt, the vote-share $x^{G}$ needed for party $i$ to be certain to gain another seat if there are $m$ seats is given by: $x_{i}{ }^{G}=\left[\left(s_{i}+1\right) /(m+1)\right]-v_{i}$ if $s_{i}<m$ and $x_{i}{ }^{G} \leq T^{E}$, otherwise not defined, where $s_{i}$ is the number of seats won by party $i, v_{i}$ is party $i$ 's vote-share, and the term $\left(s_{i}+1\right) /(m+1)$ is the Threshold of Exclusion for the $(s+1)$ th seat. In electoral systems where district-level legal thresholds $\left(T^{L}\right)$ apply, this term should correspond to the legal threshold if $s_{i}=0$ and $T^{L}>T^{E}$. Equally, legal thresholds have to be considered when calculating worst-case scenarios regarding seat losses.

For party $i$ to lose its $s$ th and final seat under the worst-case scenario, the required vote share is: $\left(v_{j}+x^{L}\right) /\left(s_{j}+1\right)=\left(v_{i}-x^{L}\right) / s_{i}$, where party $j$ is the runner-up for party $i$ 's final and $s$ th seat. Solving for $x^{L}$ yields $x_{i}^{L}=\left(-s_{i}{ }^{*} v_{j}+s_{j}{ }^{*} v_{i}+v_{i}\right) /\left(s_{i}+s_{j}+1\right)$ if $s_{i}>0$, otherwise not defined.

In general, for party $i$, the incentive for that party's supporters to turn out (given some observed or predicted vote-share allocation) can be written as: $c_{i}=\max \left[\left(T^{E}-x_{i}^{G}\right),\left(T^{E}\right.\right.$ $\left.\left.x_{i}^{L}\right)\right] / T^{E}$, where we express the vote losses and gains in the expression above as fractions of total votes cast.

If we denote the above expression, which we may take to be the Index of Competition for party $i$, as $c_{i}$, then, within any given district the overall Index of Competition, $C$, is simply a weighted average of the competition index values of the individual parties, where the weights are the $v_{i}$ values, that is, the vote-shares of each of the parties. Thus, we may write:

$$
C=\sum_{i=1}^{n} v_{i} * c_{i}
$$


Table AI (a). Switzerland: descriptive statistics of the variables used $(n=253)$

\begin{tabular}{lllll}
\hline & Mean & SD & Min & Max \\
\hline Turnout & 0.469 & 0.108 & 0.174 & 0.787 \\
District magnitude & 7.85 & 8.222 & 1 & 35 \\
Effective no. of parties (votes) & 3.98 & 1.68 & 1.03 & 7.85 \\
Index of Competition & 0.567 & 0.174 & 0.026 & 0.877 \\
Disproportionality & 0.191 & 0.135 & 0.013 & 0.671 \\
\hline
\end{tabular}

Table AI(b). Spain: descriptive statistics of the variables used $(n=468)$

\begin{tabular}{llllc}
\hline & Mean & SD & Min & Max \\
\hline Turnout & 0.74 & 0.07 & 0.41 & 0.88 \\
District magnitude & 6.73 & 5.86 & 1 & 35 \\
Threshold of exclusion & 0.17 & 0.09 & 0.03 & 0.50 \\
Effective no. of parties (votes) & 3.13 & 0.81 & 2.00 & 6.70 \\
Index of Competition & 0.61 & 0.10 & 0.30 & 0.87 \\
Disproportionality & 0.183 & 0.096 & 0.022 & 0.636 \\
\hline
\end{tabular}

\section{Appendix 2}

Table A2(a). Switzerland: bivariate correlations of the variables used $(n=253)$

\begin{tabular}{|c|c|c|c|c|c|}
\hline & $\begin{array}{l}\text { District } \\
\text { magnitude }\end{array}$ & $\begin{array}{l}\text { Threshold of } \\
\text { exclusion }\end{array}$ & $\begin{array}{l}\text { Effective no. of par- } \\
\text { ties (votes) }\end{array}$ & $\begin{array}{l}\text { Index of } \\
\text { Competition }\end{array}$ & Disproportionality \\
\hline Turnout & 0.068 & $-0.290 * * *$ & $0.105^{*}$ & 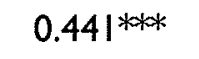 & $0.111 *$ \\
\hline $\begin{array}{l}\text { District } \\
\text { magnitude }\end{array}$ & & $-0.695 * * *$ & $0.596 * *$ & $0.109 *$ & $-0.395^{* * *}$ \\
\hline $\begin{array}{c}\text { Threshold of } \\
\text { exclusion }\end{array}$ & & & $-0.781^{* * * *}$ & $-0.396 * * *$ & $0.424 * *$ \\
\hline $\begin{array}{l}\text { Effective no. of } \\
\text { parties } \\
\text { (votes) }\end{array}$ & & & & $0.452^{* * * *}$ & -0.035 \\
\hline $\begin{array}{l}\text { Index of } \\
\text { Competition }\end{array}$ & & & & & $0.491 * * * 2$ \\
\hline
\end{tabular}

$*_{p}<0.10 ; * * 0.05 ; * * * 0.01$ 
Table A2(b). Spain: bivariate correlations of the variables used $(n=468)$

\begin{tabular}{llllll}
\hline & $\begin{array}{l}\text { District } \\
\text { magnitude }\end{array}$ & $\begin{array}{l}\text { Threshold of } \\
\text { exclusion }\end{array}$ & $\begin{array}{l}\text { Effective no. of } \\
\text { parties (votes) }\end{array}$ & $\begin{array}{l}\text { Index of } \\
\text { Competition }\end{array}$ & Disproportionality \\
\hline Turnout & 0.045 & $-0.127^{*}$ & $-0.145^{* *}$ & -0.011 & $-0.216^{* * * *}$ \\
$\begin{array}{l}\text { District magnitude } \\
\text { Threshold of } \\
\quad \text { exclusion }\end{array}$ & & $-0.640^{* * *}$ & $0.180^{* * *}$ & $-0.150^{* * *}$ & $-0.434^{* * * *}$ \\
$\begin{array}{l}\text { Effective no. of } \\
\text { parties (votes) }\end{array}$ & & $-0.220^{* * *}$ & $0.165^{* * * *}$ & $0.705^{* * * *}$ \\
$\begin{array}{l}\text { Index of } \\
\quad \text { Competition }\end{array}$ & & & -0.037 & $0.198^{* * * *}$ \\
\hline
\end{tabular}

$*_{p}<0.10 ; * * p<0.05 ; * * * p<0.01$

\section{References}

Adams, James, Samuel Merrill and Bernard Grofman (2005) A Unified Theory of Party Competition: A Cross-National Analysis Integrating Spatial and Behavioral Factors. New York: Cambridge University Press.

Amorim Neto, O. and Gary W. Cox (1997) 'Electoral Institutions, Cleavage Structures, and the Number of Parties', American Journal of Political Science 41: 149-74.

Blais, Andre (2006) 'What Affects Voter Turnout?' Annual Review of Political Science 9: 111-25.

Blais, Andre and K. Aarts (2006) 'Electoral Systems and Turnout', Acta Politica 41: 180-96.

Blais, Andre and R. K. Carty (1990) 'Does Proportional Representation Foster Turnout?' European Journal of Political Research 18: 167-81.

Blais, Andre and A. Dobrzynsky (1998) 'Turnout in Electoral Democracies', European Journal of Political Research 33: 239-61.

Blais, Andre and I. Lago (2009) 'A General Measure of District Competitiveness', Electoral Studies 28: 94-100.

Bowler, Shaun and Bernard Grofman (eds) (2000) Elections in Australia, Ireland and Malta under the Single Transferable Vote. Ann Arbor, MI: University of Michigan Press.

Brockington, D. (2004) 'The Paradox of Proportional Representation: The Effect of Party Systems and Coalitions on Individuals' Electoral Participation', Political Studies 52: 469-90.

Cox, G. W. (1997) Making Votes Count. Strategic Coordination in the World's Electoral Systems. Cambridge: Cambridge University Press.

Cox, G. W. (1999) 'Electoral Rules and the Calculus of Mobilization', Legislative Studies Quarterly 24: 387-419.

Cox, Karen E. and Leonard J. Schoppa (2002) 'Interaction Effects in Mixed-Member Electoral Systems', Comparative Political Studies 35: 1027-53.

Crepaz, Markus M. L. (1990) 'The Impact of Party Polarization and Postmaterialism on Voter Turnout', European Journal of Political Research 18: 183-205.

Foster, C. (1984) 'The Performance of Rational Voter Models in Recent Presidential Election', American Political Science Review 78: 678-90.

Franklin, Mark N. (2004) Voter Turnout and the Dynamics of Electoral Competition in Established Democracies Since 1945. Cambridge, MA: Cambridge University Press. 
Gauglhofer, M. (1988) Analyse der Sitzverteilungsverfahren bei Proportionalwahlen. Chur: Rüegger.

Geys, Benny and Bruno Heyndels (2006) 'Disentangling the Effects of Voter Fragmentation on Voter Turnout', Economics and Politics 18: 367-87.

Grofman, Bernard (1989) 'The Comparative Analysis of Coalition Formation and Duration: Distinguishing Between-Country and Within-Country Effects', British Journal of Political Science 19: 291-302.

Grofman, Bernard (2001a) 'A Note of Caution in Interpreting the Threshold of Exclusion', Electoral Studies 20: 299-303.

Grofman, Bernard (ed.) (2001b) Political Science as Puzzle Solving. Ann Arbor, MI: University of Michigan Press.

Grofman, Bernard (2001c) 'Introduction: The Joy of Puzzle Solving', in Bernard Grofman (ed.) Political Science as Puzzle Solving. Ann Arbor, MI: University of Michigan Press.

Grofman, Bernard (2004) 'Downs and Two-Party Convergence', in N. Polsby (ed.) Annual Review of Political Science 7: 25-46.

Grofman, Bernard (2009) 'Constraints on the Turnout Gap Between High and Low Knowledge (or Income) Voters: Combining the Duncan-Davis Method of Bounds with the Taagepera Method of Bounds'. Center for the Study of Democracy Working Paper, University of California, Irvine (February).

Grofman, Bernard and Peter Selb (2009) 'A Fully General Index of Political Competition', Electoral Studies 28: 291-6.

Grofman, Bernard, Robert Griffin and Christian Collet (1998) 'Analyzing the Turnout-Competition Link with Aggregate Cross-Sectional Data', Public Choice 95: 233-46.

Grofman, Bernard, Sung-Chull Lee, Edwin Winckler and Brian Woodall (eds) (1999) Elections in Japan, Korea and Taiwan under the Single Non-Transferable Vote: The Comparative Study of an Embedded Institution. Ann Arbor, MI: University of Michigan Press.

Herron, E. S. and M. Nishikawa (2001) 'Contamination Effects and the Number of Parties in Mixed-Superposition Electoral Systems', Electoral Studies 20: 63-86.

Huber, J. D., G. Kernell and E. L. Leoni (2005) 'Institutional Context, Cognitive Resources and Party Attachments Across Democracies', Political Analysis 13: 365-86.

Jackman, R. W. (1987) 'Political Institutions and Voter Turnout in Industrial Democracies', American Political Science Review 81: 405-21.

Jackman, R. W. and R. A. Miller (1995) 'Voter Turnout in the Industrial Democracies during the 1980s', Comparative Political Studies 27: 467-92.

Laakso, M. and Taagepera, R. (1979) 'The Effective Number of Parties: A Measure with Application to West Europe', Comparative Political Studies 12: 3-27.

Lago, Ignacio and Ferran Martínez (2007) 'The Importance of Electoral Rules: Comparing the Number of Parties in Spain's Lower and Upper Houses', Electoral Studies 26: 381-91.

Lijphart, A. and R. W. Gibberd (1977) 'Thresholds and Payoffs in List Systems of Proportional Representation', European Journal of Political Research 5: 219-44.

Moenius, J. and Y. Kasuya (2004) 'Measuring Party Linkage across Districts: Some Party System Inflation Indices and their Properties', Party Politics 10: 543-64.

Monroe, B. L. and A. G. Rose (2002) 'Electoral Systems and Unimagined Consequences: Partisan Effects of Districted Proportional Representation', American Journal of Political Science 46: $67-89$. 
Powell, G. B. (2000) Elections as Instruments of Democracy. Majoritarian and Proportional Visions. New Haven, CT: Yale University Press.

Simpson, E. H. (1951) 'The Interpretation of Interacting Contingency Tables', Journal of the Royal Statistical Society, B, 13: 238-41.

Taagepera, Rein (1997) 'Effective Number of Parties for Incomplete Data', Electoral Studies 16: 145-51.

Taagepera, Rein (2007) Predicting Party Sizes: The Logic of Simple Electoral Systems. Oxford: Oxford University Press.

Taagepera, Rein and Matthew Shugart (1989) Seats and Votes. The Effects and Determinants of Electoral Systems. New Haven, CT: Yale University Press.

Tsebelis, George (1988) 'Nested Games: The Cohesion of French Electoral Coalitions', British Journal of Political Science 18: 145-70.

Wainer, Howard and Lisa M. Brown (2004) 'Two Statistical Paradoxes in the Interpretation of Group Differences: Illustrated with Medical School Admission and Licensing Data', American Statistician 58 (May): 117-23.

\section{Author biographies}

Bernard Grofman is Professor of Political Science at the University of California, Irvine, where he has taught since 1976. Much of his work has dealt with issues of elections and voting rules, voting rights and redistricting. He is the author of over 200 articles and research notes, coauthor of Minority Representation and the Quest for Voting Equality (1992), A Unified Theory of Voting (1999), A Unified Theory of Party Competition (2005) and Behavioral Social Choice (2006). He has edited or co-edited 17 other books, including Quiet Revolution in the South (1995) (an empirical evaluation of the impact of the Voting Rights Act on minority representation in municipal elections, co-edited with Chandler Davidson) and Political Gerrymandering and the Courts (1990). Professor Grofman was chair of the Section on Representation and Electoral Systems of the American Political Science Association in 1993-4. His work on voting rights and in volumes he has edited has been cited repeatedly by federal courts, including the United States Supreme Court in a dozen different cases - perhaps most notably in Thornburg v. Gingles, 478 U.S. 30 (1986). He has testified as an expert witness in redistricting and voting rights cases in more than a dozen states. He is a Fellow of the American Academy of Arts and Sciences and Past President of the Public Choice Society.

Peter Selb is a Junior Professor of Political Methodology in the Department of Politics and Management, University of Konstanz, Germany. Research interests include political behaviour and public opinion. Recent publications have appeared in Electoral Studies, European Journal of Political Research, European Political Science Review, Political Behavior and Public Choice. 